\title{
Analisis Tingkat Stres dan Performansi berdasarkan Kecepatan Respon dan Jumlah Kesalahan serta Hubungannya pada Pengemudi Mobil Pribadi di Bandung
}

\section{Stress Analysis and Performance Level based on Reaction Time and Number of Error with Correlation in Bandung Personal Car Driver}

\author{
Asterina Febrianti*, Rizkia Rahayu \\ Program Studi Teknik Industri, Fakultas Teknik Industri, Institut Teknologi Nasional
}

INFO ARTIKEL

Article history:

Diterima 19-03-2019

Diperbaiki 15-04-2019

Disetujui 15-05-2019

Kata Kunci:

stres, performansi, salivary

alpha amilase, stroop test
ABSTRAK

Badan Intelegensi Negara (BIN) menyatakan bahwa salah satu penyebab utama kecelakaan lalu lintas yaitu faktor kelalaian pengemudi. Data terdahulu menunjukkan sepanjang 2018 mengalami peningkatan 4,69\% dibandingkan pada tahun 2017. Pengukuran menggunakan indikator salivary alpha amylase dengan menggunakan cocorometer diketahui dapat mengukur tingkat stres pengemudi dalam berkendara disertai dengan penurunan perfomansi melalui indikator waktu respon dan jumlah kesalahan menggunakan stroop test. 16 orang partisipan diuji dengan klasifikasi memiliki SIM A dengan rentang usia 19-25 tahun dan memiliki pengalaman mengemudi minimal 2 tahun. Hasil penelitian untuk treatment tidur cukup dan treatment tidak tidur baik sebelum dan setelah simulasi pada tingkat stres dan tingkat performansi menunjukan perbedaan yang signifikan. Sementara untuk tingkat stress antara treatment tidur cukup dan tidak tidur pada sebelum dan setelah simulasi menunjukan perbedaan yang signifikan dan untuk tingkat performansi menunjukan perbedaan yang signifikan. Hubungan antara tingkat stres dan tingkat performansi dengan nilai koefisien korelasi sebesar 0,4, artinya terdapat hubungan yang kuat antara tingkat stres dan tingkat perfomansi. Implikasi penelitian ini menunjukan bahwa jika pengemudi mobil pribadi mengalami peningkatan tingkat stres maka performansi pengemudi akan menurun saat berkendara. Penelitian ini diharapkan menjadi masukan bagi stakeholder terkait dalam membuat regulasi pengemudi mobil pribadi saat berkendara agar tingkat kecelakaan yang terjadi dapat berkurang.
Keywords:

stress, performance, salivary alpha amilase, stroop test

\section{ABSTRACT}

Badan Intelegensi Negara (BIN) stated that one of the main causes of trafiic accidents is the driver's negligence. Previous data shows that the number of accidents during 2018 increased $4.69 \%$ compared to 2017. Measurements using the salivary alpha amylase indicator by using cocorometer are known to be able to measure the stress level of the driver by driving accompanied by decreased in performance that can be measured through indicator reaction time and number of errors using the stroop test. 16 participants were tested with the classification of having a driving license (SIM A) with an age range of 16-29 years and having minimum of 2 years driving experience. The results showed for adequate sleep treatment and nonsleep treatment both before and after the simulation at stress level and performance level showed a significant difference. As for stress levels $\mathrm{p}$-value between treatment of adequate sleep and no sleep before and after the simulation showed significant differences and for the level $\mathrm{f}$ performance showed a significant difference. The relationship between stress level and performance levels with a correlation coefficient of 0.4 , indicate there is a strong relationship between stress level and performance level. The implication of this study indicates that the increase of stress level will decrease driving performance. This research is expected to be an input for related stakeholder in making regulation of personal car drivers when driving so that the level of accidents that occur can be reduced. 


\section{Pendahuluan}

Mengemudi meliputi aktivitas yang melibatkan beberapa komponen diantaranya pengemudi, kendaraan, penumpang, jalan, dan lingkungan sekitar yang saling berinteraksi. Jika komponen tersebut tidak berinteraksi dengan baik maka dapat menimbulkan risiko kecelakaan saat mengemudi. Berdasarkan situs Badan Intelegensi Negara (BIN) dikatakan bahwa salah satu yang menjadi penyebab utama kecelakaan lalu lintas yaitu faktor kelalaian pengemudi. Kecelakaan yang diakibatkan oleh faktor pengemudi mencapai 93,52 \%, diantaranya yaitu lengah, mengantuk, tidak terampil, lelah, mabuk, kecepatan tinggi, tidak menjaga jarak, kesalahan pejalan, dan gangguan binatang [1].

Data Polrestabes Kota Bandung periode Februari 2014 hingga Februari 2015 menunjukan bahwa tingkat kecelakaan khususnya mobil pribadi mengalami peningkatan secara fluktuatif. Namun kecenderungan data kecelakaan yang terjadi pada mobil pribadi mengalami peningkatan setiap tahunnya. Data Polrestabes Kota Bandung menunjukan bahwa kecelakaan yang terjadi baik pada pelaku maupun korban terdapat pada rentang usia $16-30$ tahun. Pada tahun 2015 dari 296 kecelakaan mobil pribadi $94 \%$ diantaranya merupakan kecelakaan yang dialami oleh usia $16-30$ tahun dan $6 \%$ lainnya dialami oleh usia diatas 30 tahun. Badan Pusat Statistik tahun 2018 melalui Korlantas POLRI mencatat jumlah kecelakaan sepanjang 2018 mengalami peningkatan 4,69\% dibandingkan pada tahun 2017.

Faktor pengemudi yang menjadi penyebab kecelakaan kemungkinan besar karena kelelahan. Kelelahan disebabkan beban kerja yang diterima melebihi kapasitas manusia [2]. Terdapat dua klasifikasi kelelahan pada pengemudi yaitu fokus yang tinggi perhatian pengemudi terforkus pada kegiatan mengemudi yang berarti peformansi dari pengemudi baik, selanjutnya pengemudi akan mengalami awal penurunan fokus dan performansi yang nampak mengantuk (drowsy) dan pada tahap ini terjadi penurunan perhatian sehingga mengemudikan kendaraan tidak terkontrol (gazingvacantly at one unspecified point) [3]. Kelelahan merupakan masalah penting yang berdampak pada inefisiensi dan risiko kecelakaan [4]. Risiko dari kelelahan kerja tersebut salah satunya adalah terjadi stres [5].

Stres adalah bagian dari hidup kita sehari-hari yang tidak dapat dipisahkan dari seluruh aktivitas dari bangun hingga kembali tidur, dan stres dapat berakibat positif maupun negatif [6]. Stres pada pengemudi merupakan hasil dari proses interaksi dinamis antara factor personal dan lingkungan yang diperantarai proses kognitif [7]. Pengemudi yang mengalami stres merupakan hasil dari proses interaksi dinamis antara faktor personal dan lingkungan yang diperantarai proses kognitif [8]. Terdapat lima bentuk stres mengemudi, yaitu ; aggression merupakan reaksi berupa perasaan marah dan frustrasi sehingga menimbulkan perilaku berbahaya yang menunjukkan ketidaksabaran [8]; dislike driving merupakan penilaian negatif dari pengemudi sehingga menimbulkan mood negatif yang cenderung mengganggu performansi mengemudi [9], hazard monitoring diartikan sebagai kesadaran atau pantauan akan bahaya [10], thrill seeking merupakan faktor yang berkaitan dengan kepribadian mencari sensasi [10]; dan fatigue proneness merupakan kondisi dimana seorang pengemudi menjadi rentan kelelahan fisik dan mental setelah melakukan perjalanan yang cukup panjang [10]. Ketika seseorang mengalami lima bentuk stres maka konsentrasi terhadap yang akan dilakukan juga menurun sama halnya dengan mengemudi ketika pengemudi mengalami stres di perjalanan maka pengemudi tersebut sulit untuk berkonsentrasi pada saat mengemudi. Stres yang berlebihan dapat menyebabkan terjadinya penurunan performansi yang dapat meningkatkan risiko kecelakaan [11].

Dampak dari stres dapat mengganggu performansi mengemudi yang ditimbulkan dari mood [9]. Kondisi ini dapat dicerminkan dalam kecemasan sehingga dirinya merasa tidak nyaman dan tidak yakin dalam mengemudi. Misalnya seseorang yang cemas ketika akan mengemudi karena cuaca yang mendung. Performansi saat mengemudi juga dapat ditimbulkan perilaku membahayakan yang menunjukkan ketidaksabaran dan diakibatkan dari reaksi berupa perasaan marah dan frustasi [8]. Selain itu, perilaku membahayakan yang ditunjukan oleh pengemudi dapat menyebabkan kecelakaan lalu lintas. Hal ini dapat disebabkan oleh dampak stres yang dapat mempengaruhi performansi menurun. Oleh karena itu, diperlukan penelitian untuk mengidentifikasi tingkat stress dan tingkat performansi serta pengaruh stres terhadap performansi dengan indikator salivary alpha amylase dan waktu respon khususnya pada pengemudi mobil pribadi.

\section{Studi Literatur}

\subsection{Posisi dan Kontribusi Penelitian}

Siswanto dan Tesravita (2015) melalui penelitian dengan tujuan mengevaluasi tingkat kelelahan dan tingkat stres pengemudi Travel X-trans dan masinis berdasarkan hasil PSQI, KSS, dan pengukuran denyut jantung. Penelitian dilakukan secara subjektif (PSQI dan KSS) dan secara objektif (pengukuran denyut jantung). Penelitian tersebut menunjukan bahwa pengemudi dan masinis mengalami kantuk yang cukup tinggi, kondisi pekerjaan yang dialami dapat memicu stres yang akhirnya mempengaruhi mental pengemudi dan masinis. [37]

Maulana (2019) melalui penelitiannya memiliki tujuan pengukuran beban kerja mental sopir bus menggunakan metode SWAT (Studi Kasus di PO. XYZ). Penelitian ini dilakukan secara subjektif (metode SWAT). Penelitian tersebut menunjukan bahwa faktor beban kerja mental yang paling mempengaruhi sopir bus dalam berkendara ialah time load dengan presentase sebesar $71.02 \%$ dan diperoleh nilai SWAT rescale yang tinggi "kemacetan lalu lintas" sebaiknya perusahaan memfasilitasi setiap bus dengan GPS atau alat pendeteksi kemacetan. [38]

Penelitian ini memiliki tujuan menganalisis tingkat stres dan tingkat performansi serta pengaruh tingkat stres terhadap tingkat performansi pada pengemudi mobil pribadi dengan menggunakan indikator salivary alpha amylase dan waktu respon. Penelitian ini dilakukan dengan melihat tingkat stres dan tingkat performansi serta hubungannya pada pengemudi mobil pribadi di Kota Bandung. Penelitian sebelumnya yang relevan tidak membahas keterkaitan antara tingkat stres dan tingkat performansi pada pengemudi mobil pribadi 
khususnya di Kota Bandung. Penelitian ini menggunakan pengukuran secara objektif dibandingkan penelitian sebelumnya, dimana penelitian objektif dianggap lebih akurat dalam mendeteksi baik tingkatt stress dan tingkat performansi.

\subsection{Ergonomi}

Ergonomi memiliki beberapa pengertian menurut para ahli, diantarannya adalah:

1. Menjelaskan ergonomi merupakan cabang ilmu yang sistematis memanfaatkan informasi - informasi mengenai sifat, kemampuan dan keterbatasan manusia dalam merancang suatu sistem kerja sehingga orang dapat hidup dan bekerja pada sistem tersebut dengan baik, yaitu mencapai tujuan yang diinginkan memalui pekerjaan itu, dengan efektif, nyaman, aman dan sehat (ENASE) [12].

2. Menjelaskan bahwa ergonomic merupakan suatu aktivitas multidisiplin yang diarahkan untuk mengumpulkan informasi tentang kapasitas dan kemampuan manusia, dan memanfaatkannya dalam merancang pekerjaan, produk, tempat kerja, dan peralatan kerja [13].

3. Mendefiniskan ergonomi merupakan suatu disiplin yang mengkaji keterbatasan, kelebihan, serta karakteristik manusia, dan memanfaatkan informasi tersebut dalam merancang produk, mesin, fasilitas, lingkungan, dan bahkan sistem kerja, dengan tujuan utama tercapainya kualitas kerja yang terbaik tanpa mengabaikan aspek kesehatan, keselamatan, serta kenyaman manusia penggunanya [13].

\subsection{Cakupan Ergonomi}

Ergonomi kognitif (Human Information Processing) merupakan kajian bidang ergonomi yang memperlajari bagaimana manusia memproses informasi dan lingkungannya, dimulai dari tahap mengindra adanya stimulus dan mempersepsikannya, sampai dengan mengambil keputusan dan melakukan tindakan yang diperlukan [13]. Terdapat 3 tahapan besar dalam memproses informasi, yaitu: (1) memahami informasi apa yang diberikan lingkungan, (2) memproses informasi tersebut pada tingkatan yang lebih tinggi, dan (3) memberikan respon atas informasi tersebut [13]. Berikut merupakan model Human Information Processing:

\subsection{Kelelahan}

Kelelahan adalah suatu mekanisme perlindungan agar tubuh terhindar dari kerusakan lebih lanjut sehigga terjadi proses pemulihan setelah istirahat [5]. Kelelahan merupakan terjadinya penurunan performansi dan perasaan subjektif yang ditimbulkan dari pekerjaan yang berkepanjangan dan stres [14]. Lembaga Mountain Stet Centersfor Living menyatakan bahwa kelelahan adalah penurunan kemampuan atau keengganan yang kuat dalam menanggapi situasi karena altivitas yang berlebihan sebelumnya baik secara mental, secara fisik maupun secara emosional [15]. National Transport Comission menjelaskan bahwa kelelahan sebagai keadaan yang terus menerus lelah sehingga dibutuhkan istirahat untuk memulihkan efek dari kelelahan seperti kurangnya kewaspadaan, penurunan daya ingat, perubahan suasana hati (mood), tertidur saat mengemudi, mengantuk saat mengemudi dan penurunan pertimbangan atau pemikiran [16].

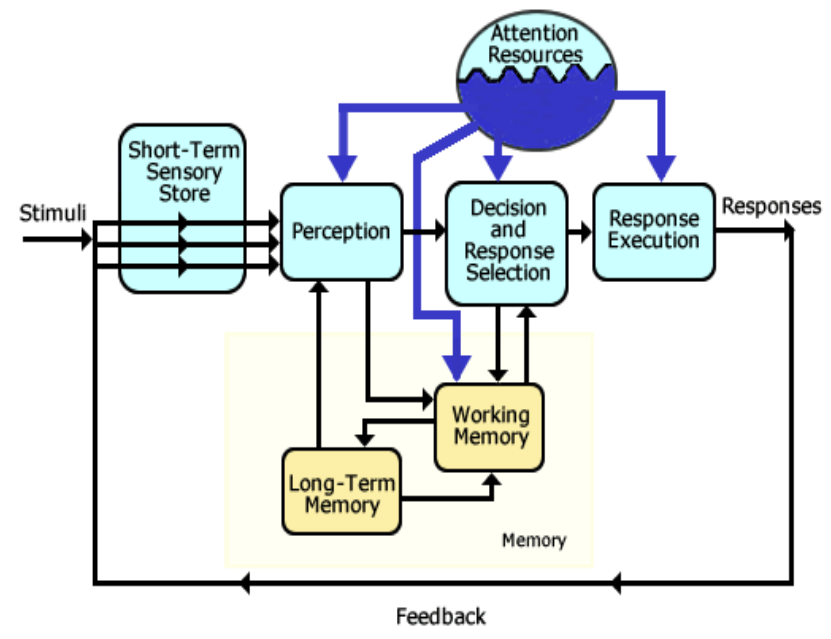

Gambar 1. Model human information processing [13]

\subsection{Stress}

Stres adalah segala rangsangan atau aksi tubuh manusia baik yang berasal dari luar maupun dari dalam tubuh itu senddiri yang dapat menimbulkan bermacam-macam dampak yang merugikan mulai dari menurunnya kesehatan sampai kepada dideritanya suatu penyakit [5]. Stres dapat terjadi ketika permintaan dalam hidup melebihi kemampuan diri kita untuk memenuhi permintaan tersebut [17]. Stres merupakan interaksi antara manusia dan lingkungan atau pekerjaannya dengan kesadaran tidak dapat memenuhi kebutuhan bagian lingkungan atau pekerjaan tersebut dan ini menjadi perhatian manusia yang dapat menyebabkan respon emosional yang negative [18]. Irama bioloigis tubuh juka akan mempengaruhi ketahanan tubuh terhadap stres yang dialami [19]. Stres sendiri dapat diklasifikasikan menjadi stress tubuh manusia dan stres sel, stres prikologis dan stress fisik, dan eustress dan distress [20].

\subsection{Salivary Alpha Amilase}

Salivary Alpha Amilase merupakan salah satu cara yang dapat digunakan untuk mengukur stress. Saat ini pengukuran stres banyak menggunakan alat ukur hormone stres seperti kortisol dan katekolamin. Peningkatan proses metabolisme dalam kondisi stres juga akan meningkatkan produksi hormone epinephrine dan norephinephrine yang tergabung sebagai hormon katekolamin [21]. Sementara untuk hormon kortisol dikeluarkan pada kondisi stres dalam rangka membantu otak menyediakan glukosa [19]. Menyebutkan bahwa dalam proses metabolisme yang besar, semua sel tubuh akan dapat menggunakan asam lemak dan asam amino yang ada, akan tetapi pada sel otak harus terdapat glukosa [19]. Pengukuran stres menggunakan hormon kortisol dan katekolamin saat ini sangat dipertimbangkan karena pengukurannya melalui pengambilan darah dan terdapat indikator lain yang dapat digunakan untuk mengukur stres yaitu indikator amylase melalui air liur dalam mulut [22]. 


\subsection{Performansi Manusia}

Human performance atau performansi manusia merupakan kemampuan setiap orang untuk memenuhi kebutuhan pekerjannya [23]. Jika dilihat dari perspektif sebuah sistem, performansi manusia dapat dipahami sebagai bagian sebuah transformasi proses diantara input dan output [23].

\subsection{Stroop Test}

The stroop color-word interference test adalah penugasan kognitif banyak yang digunakan untuk penilaian fungsi pengaturan, khususnya untuk perhatian yang selektif dan control kognitif dari proses ototmatis [25]. Stroop test biasa digunakan penelitian kognitif sebagai pola pikir untuk menginvestigasi penugasan fungsi kontrol, khususnya sebagai gangguan keputusan antara dimensi stimulus, respon halangan, dan pemilihan respon [25].

\subsection{Uji t Dua Sampel Berpasangan}

Uji T dua sampel berpasangan digunakan terhadap dua sampel dengan subyek yang sama namun memiliki perlakuan yang berbeda [26]. Pengujian dilakukan pada parameter tingkat stres dan tingkat performansi. Pegujian dilakukan untuk melihat perbedaan antara sebelum dan setelah simulasi, shift pagi-siang-sore, serta perlakuan tidur cukup dan tidak tidur.

\subsection{Uji Koefisien Korelasi}

Koefisien korelasi merupakan angka yang menunjukan tinggi atau rendahnya hubungan antara dua variavel atau lebih. Kriteria mengenai kekuatan hubungan antara 2 variabel dapat dikategorikan sebagai berikut: $0-<0,20$ (hubungan sangat lemah (dapat diabaikan); $\geq 0,20-<0,40$ (hubungan rendah); $\geq$ $0,40-<0,70$ (hubungan cukup); $\geq 0,70-<0,90$ (hubungan kuat) [27].

\subsection{Uji Regresi Linear Sederhana}

Tujuan utama analisis regresi sederhana ialah untuk mengukur intensitas hubungan antara 2 variabel dan membuat prediksi maupun dugaan nilai dependen $(\mathrm{Y})$ atas dasar nili independden (X) [28]. Analisis korelasi bertujuan untuk mengukur kekuatan dan tingkatan hubungan linear antara dua variable [29].

\section{Metode Penelitian}

\subsection{Identifikasi Metode Penelitian}

Parameter yang digunakan dalam penelitian ini adalah tingkat stres dan performansi. Tabel I dan Tabel II merupakan perbandingan instrumen yang digunakan dalam penelitian. Untuk tingkat stres menggunakan indikator salivary alpha amilase dikarenakan varian yang dihasilkan lebih kecil serta pengambilan datanya lebih mudah dibandingkan indikator hormon kortisol. Pengambilan salivary alpha amilase dilakukan dengan menggunakan alat cocorometer yang diambil di bawah lidah partisipan. Sementara untuk tingkat performansi menggunakan indikator waktu reaksi dengan alat pengukuran stroop test. Instrumen ini digunakan karena waktu yang digunakan relatif singkat dan cukup akurat dibandingkan dengan instrumen lain (Tabel 2). Pengukuran waktu reaksi dengan Instrumen stroop test menggunakan aplikasi pada handphone.

\subsection{Identifikasi Karakteristik Partisipan}

Karakteristik partisipan pada penelitian ini, adalah:

1. Memilki surat izin mengemudi (SIM A) yang dikeluarkan oleh Kepolisian Republik Indonesia

2. Rentang usia partisipan 19-25 tahun (usia mahasiswa/mahasiswi)

3. Memiliki pengalaman mengemudi minimal 2 tahun

\subsection{Desain Sampling}

Penelitian dilakukan dengan pengambilan sampel yang berhubungan dengan data klinis objek penelitian. Jumlah partisipan dalam penelitian klinis dibatasi karena pertimbangan etis, biaya dan waktu [34]. Pendekatan tersebut ialah:

$$
n=\frac{2\left[(a+b)^{2} \sigma^{2}\right]}{\left(\mu_{1}-\mu_{2}\right)^{2}}
$$

Dengan taraf signifikansi (a) $5 \%=1,96$, nilai $\mathrm{b}=0,842$ [34], nilai $\sigma=8,8$ [30], Nilai $\mu_{1}-\mu_{2}=15 \mathrm{kU} / \mathrm{L}$ [31]. Berdasarkan nilai tersebut maka perhitungan jumlah sampelnya ialah sebagai berikut:

$$
n=\frac{2\left[(1,96+0,842)^{2} 8,8^{2}\right.}{15^{2}}=5,40 \text { Partisipan }
$$

\subsection{Teknik Sampling}

Teknik sampling yang digunakan adalah purposive sampling dimana teknik penentuan sampel dengan beberapa pertimbangan tertentu yang bertujuan agar data yang diperoleh akan lebih representative [35].

\subsection{Desain Eksperimen}

Desain eksperimen penelitian ini ialah:

1. Sebelum simulasi dimulai partisipan diberikan perlakuan berupa pengujian tingkat stres (enzim amiase) menggunakan cocorometer dan tingkat performansi menggunakan stroop task.

2. Simulasi dilakukan selama 60 menit/partisipan/waktu kerja

3. Setelah simulasi diberikan perlakuan berupa pengujian yang sama saat sebelum dilakukan simulasi.

\subsection{Metode Pengumpula Data}

Metode pengumpulan data yang digunakan ialah metode kuantitatif yang dapat diartikan sebagai metode penelitian yang berlandaskan pada filsafat positifme, digunakan untuk meneliti populasi atau sampel tertentu, pengumpulan data menggunakan instrumen penelitian, analisis data bersifat kuantitatif/statistik, dengan tujuan untuk menguji hipotesis yang telah ditetapkan [35].

\subsection{Persiapan Peralatan (Simulator) Penelitian}

Peralatan penelitian yang digunakan ialah sebagai berikut:

1. Driving controller (tipe Logitech MOMO RACING) terdiri dari steering wheels (dapat berputar hingga $900^{\circ}$ seperti mobil nyata), pedal gas dan rem. Perseneling menggunakan dua transmisi (pedal gas dan pedal rem) seperti mobil automatic. 
2. City car driving (aplikasi simulator) dengan kondisi yang digunakan saat simulasi dapat dikondisikan dengan kondisi sebenarnya.

3. Infokus yang berfungsi menghasilkan gambar dari laptop yang digunakan ke layar infokus.

4. Layar infokus berfungsi menampilkan gambar dari infokus, layar yang digunakan berukuran $250 \mathrm{~cm} \times 150$ $\mathrm{cm}$. Layar infokus diletakkan $150 \mathrm{~cm}$ didepan meja partisipan.

5. Kursi lipat chitose (dikondisikan semedikian rupa seperti jok mobil)

6. Meja yang digunakan merupakan meja dari Laboratorium Analisis Perancangan Kerja dan Ergonomi.

7. Cocorometer, digunakan untuk mengukur tingkat stress pratisipan dengan menggunakan air liur partisipan.

8. Stroop task, digunakan untuk mengukur performansi partisipan.

\subsection{Prosedur Simulasi}

Prosedur simulasi pada penelitian ini meliputi:

1. Pelaksanaan dimulai dari pukul 07.00-18.00

2. Setiap partisipan akan melakukan simulasi dengan selama 1 (satu) jam untuk masing-masing shift yang diberikan (pagi, siang, sore) dengan 2 kondisi yang berbeda

a. Kondisi 1 (satu) yaitu malam hari sebelum penelitian partisipan memiliki waktu tidur cukup

b. Kondisi 2 (dua) yaitu malam hari sebelum penelitian partisipan memiliki waktu tidur kurang

\section{Hasil dan Pembahasan}

Responden yang digunakan dalam penelitian ini ialah sebanyak 16 orang, dengan melihat rumus 1 nilai sampel yang didapat ialah sebanyak 6 orang. Berdasarkan hal tersebut maka data yang digunakan sudah cukup memenuhi untuk diproses pada pengolahan data. Pengujian dilakukan pada 2 parameter yaitu parameter stres dan parameter performansi dengan beberapa proses uji statistik sebagai berikut:

\subsection{Tingkat Stres}

Pengujian dilakukan untuk mengetahui pengaruh tingkat stress pada pengemudi mobil pribadi saat simulasi dan setelah simulasi untuk shift pagi, shift siang, dan shift sore dengan masing-masing treatment tidur cukup dan treatment tidak tidur. Berikut ini merupakan perhitungan uji statistik yang digunakan:

1. Uji Normalitas

Treatment tidur cukup dan tidak tidur baik untuk shift pagi, siang, dan sore menunjukkan bahwa data responden berdistribusi normal.

2. Uji t berpasangan dua sisi

Pengujian dilakukan sebanyak 3 kali, yaitu: sebelum simulasi dan setelah simulasi dengan treatment tidur cukup menunjukan perbedaaan tingkat stres ( $p$-value (sig.) $>\alpha$, $0,174>0,05)$; sebelum simulasi dan setelah simulasi dengan treatment tidak tidur menunjukan perbedaan tingkat stress ( $p$-value (sig.) $>\alpha, 0,351>0,05$ ); treatment tidur cukup dengan treatment tidak tidur untuk shift pagi ( $p$-value (sig.) $>\alpha, 0,709>0,05)$, siang ( $p$-value (sig.) $>\alpha$, $0,340>0,05)$ dan malam ( $p$-value (sig.) $>\alpha, 0,661>0,05)$ menunjukan perbedaan tingkat stress pada masing-masing shift. (Treatment tidur cukup) shift pagi- shift siang ( $p$ value (sig.) $>\alpha, 0,812>0,05)$, shift pagi- shift sore ( $p$ value (sig.) $>\alpha, 0,121>0,05)$, dan shift siang- shift sore ( $p$-value (sig.) $>\alpha, 0,251>0,05)$ menunjukan perbedaan stress yang signifikan; (treatment tidak tidur) shift pagishift siang ( $p$-value (sig.) $>\alpha, 0,028<0,05)$, shift pagishift sore ( $p$-value (sig.) $>\alpha, 0,084<0,05)$, shift siangshift sore ( $p$-value (sig.) $>\alpha, 0,883>0,05)$, hanya shift siang- shift sore yang menunjukan perbedaan stres yang signifikan.

Tabel 1

Indikator stres

\begin{tabular}{cll}
\hline Indikator Stres & \multicolumn{1}{c}{ Kelebihan } & \multicolumn{1}{c}{ Kekurangan } \\
\hline Hormon Kortisol & $\begin{array}{l}\text { Tidak sensitif terhadap makanan dan air, sebagai } \\
\text { hormon utama stres, mudah berdifusi melalui } \\
\text { membran sel }\end{array}$ & $\begin{array}{l}\text { Membutuhkan biaya yang tidak sedikit, tidak semua } \\
\text { partisipan menyetujui untuk diambil sampel darahnya, } \\
\text { pengambilan darah juga dapat menimbulkan stres } \\
\text { sehingga hasil pengukuran menjadi bias }\end{array}$ \\
\hline $\begin{array}{c}\text { Salivary Alpha } \\
\text { Amylase }\end{array}$ & $\begin{array}{l}\text { Lebih mudah untuk pengukurannya, tidak } \\
\text { membutuhkan waktu yang lama, sifat sensitif } \\
\text { terhadap makanan dan air dapat diantisipasi dengan } \\
\text { mudah }\end{array}$ & $\begin{array}{l}\text { Membentu varian kesalahan pada pengukuran terutama } \\
\text { ruangan }\end{array}$ \\
\hline
\end{tabular}

Tabel 2

Instrumen performansi

\begin{tabular}{|c|c|c|c|}
\hline $\begin{array}{l}\text { Instrumen } \\
\text { performansi }\end{array}$ & Kelebihan & Kekurangan & Keluaran data \\
\hline $\begin{array}{l}\text { PVT (Phsychomotoric } \\
\quad \text { Vigiliance Test) }\end{array}$ & $\begin{array}{l}\text { Sederhana dalam pelaksanaannya } \\
\text { membutuhkan waktu relatif yang sedikit. }\end{array}$ & $\begin{array}{l}\text { Karena terlalu sederhana sering terjadi false start } \\
\text { (kesalahan tanggap sebelum rangsangan } \\
\text { diberikan) }\end{array}$ & Waktu reaksi \\
\hline Flickr & $\begin{array}{l}\text { Menguji daya tahan waspada dan konsentrasi } \\
\text { partisipan }\end{array}$ & $\begin{array}{l}\text { Waktu yang dibutuhkan untuk melakukan tes } \\
\text { relatif lama }\end{array}$ & $\begin{array}{c}\text { Frekuensi kedipan } \\
\text { lampu yang dideteksi }\end{array}$ \\
\hline Stroop Task & $\begin{array}{l}\text { Sangat menuntut konsentrasi partisipan sehingga } \\
\text { hasil yang dimiliki akurat dan waktu yang } \\
\text { relative lebih singkat }\end{array}$ & $\begin{array}{l}\text { Tes ini lebih mengarah kepada kecepatan } \\
\text { persepsi daripada kecepatan reaksi }\end{array}$ & Waktu reaksi \\
\hline $\begin{array}{c}\text { MVT (Mackworth } \\
\text { Clock Vigilance Task) }\end{array}$ & $\begin{array}{l}\text { Sedikit lebih kompleks daripada PVT sehingga } \\
\text { hasil lebih valid daripada PVT }\end{array}$ & Memakan waktu relatif lama & Waktu reaksi \\
\hline
\end{tabular}




\section{Uji Manova}

Indikator pengujian homogenitas varians menunjukan tidak terdapat perbedaan yang signifikan pada variabel dependen (stress) antara treatment tidur dan treatment tidak tidur pada sebelum dan setelah simulasi sama $(p$ value (sig.) $>\alpha, 0,513>0,05 ; 0,108>0,05)$. Sementara indikator pengujian homogenitas kovarians menujukan hasil bahwa kovarians dari variabel tingkat stress tidak sama ( $p$-value (sig.) $>\alpha, 0,045<0,05)$. Multivariate test menunjukan terdapat perbedaan yang signifikan variabel tingkat stres antara treatment tidur dan treatment tidak tidur pada sebelum dan setelah simulasi ( $p$-value (sig.) $>\alpha$, $0,365>0,05)$.

\subsection{Tingkat Performansi}

Pengujian dilakukan untuk mengetahui pengaruh tingkat performansi pada pengemudi mobil pribadi saat simulasi dan setelah simulasi untuk shift pagi, shift siang, dan shift sore dengan masing-masing treatment tidur cukup dan treatment tidak tidur. Tingkat performansi berdasarkan kecepatan respon dan jumlah kesalahan menunjukan bahwa partisipan 1, 2, 3, 4, 5, 7, 9 dan 10 masih melakukan kesalahan pada treatment tidur dan tidak tidur pada shift pagi, siang, dan sore. Berikut ini merupakan perhitungan uji statistik yang digunakan:

\section{Uji Normalitas}

Treatment tidur cukup dan tidak tidur baik untuk shift pagi, siang, dan sore menunjukkan bahwa data responden berdistribusi normal.

2. Uji t berpasangan dua sisi

Pengujian dilakukan sebanyak 3 kali, yaitu: sebelum simulasi dan setelah simulasi dengan treatment tidur cukup menunjukan perbedaaan tingkat performansi ( $p$-value (sig.) $>\alpha, 0,546>0,05)$; sebelum simulasi dan setelah simulasi dengan treatment tidak tidur menunjukan perbedaan tingkat performansi ( $p$-value (sig.) $>\alpha, 0,904>$ $0,05)$; treatment tidur cukup dengan treatment tidak tidur untuk shift pagi ( $p$-value (sig.) $>\alpha, 0,171>0,05)$, siang $(p$ value (sig.) $>\alpha, 0,306>0,05)$ dan malam ( $p$-value (sig.) $>$ $\alpha, 0,054>0,05)$ menunjukan perbedaan tingkat performansi untuk masing-masing shift. (Treatment tidur cukup) shift pagi- shift siang ( $p$-value (sig.) $>\alpha, 0,772>$ $0,05)$, shift pagi- shift sore ( $p$-value (sig.) $>\alpha, 0,186>$ $0,05)$, dan shift siang- shift sore ( $p$-value (sig.) $>\alpha, 0,446>$ $0,05)$ menunjukan perbedaan tingkat performansi yang signifikan; (treatment tidak tidur) shift pagi- shift siang ( $p$ value (sig.) $>\alpha, 1,000>0,05)$, shift pagi- shift sore $(p$ value (sig.) $>\alpha, 0,886>0,05)$, dan shift siang- shift sore ( $p$-value (sig.) $>\alpha, 0,914>0,05$ menunjukan perbedaan tingkat performansi yang signifikan.

3. Uji Manova

Indikator pengujian homogenitas varians menunjukan tidak terdapat perbedaan yang signifikan pada variabel dependen (performansi) antara treatment tidur dan treatment tidak tidur pada sebelum dan setelah simulasi sama ( $p$-value (sig.) $>\alpha, 0,957>0,05 ; 0,638>0,05)$. Sementara indikator pengujian homogenitas kovarians menujukan hasil bahwa kovarians dari variabel tingkat performansi adalah sama ( $p$-value (sig.) $>\alpha, 0,559>0,05)$. Multivariate test menunjukan terdapat perbedaan yang signifikan variabel tingkat performansi antara treatment tidur dan treatment tidak tidur pada sebelum dan setelah simulasi ( $p$-value (sig.) $>\alpha, 0,915>0,05)$.

\subsection{Koefisien Korelasi}

Untuk mengetahui seberapa besar hubungan tingkat stress (variabel independen) dengan tingkat performansi (variabel dependen) maka dilakukan perhitungan koefisien korelasi. Hasil menunjukan nilai sebesar $-0,4$ yang artinya hubungan tingkat stres dan performansi cukup kuat.

\subsection{Regresi Linear Sederhana}

Persamaan regresi linear yang didapat dengan menggunakan perangkat lunak SPSS 17.0 menghasilkan persamaan yaitu $\mathrm{Y}=0,170-0,025 \mathrm{X}$. Nilai kemiringan yang dihasilkan adalah - 0,025 dengan nilai konstanta sebesar 0,17. Nilai konstanta 0,17 menunjukan besarnya variabel rata-rata tingkat performansi tidak dipengaruhi oleh tingkat stres (ketika nilainya 0 ). Setiap peningkatan 1 kilo unit/liter tingkat stress maka akan berpengaruh terhadap penurunan tingkat performansi sebesar -0,025 menit. Sebaliknya jika penururnan tingkat stres sebesar 1 kilo unit/liter akan berpengaruh terhadap peningkatan performansi sebesar 0,025 menit. Hal tersebut diakibatkan dari hubungan yang berbanding terbalik dari tingkat stres dan tingkat performansi.

\section{5. kesimpulan}

Hasil penelitian pada pengemudi mobil di Bandung menunjukan bahwa terdapat perbedaan tingkat stres yang signifikan untuk treatment tidur cukup dan treatment tidak tidur baik sebelum simulasi dan setelah simulasi. Sementara untuk treatment tidur cukup menunjukan perbedaan yang signifikan antar shift dan untuk treatment tidak tidur hanya shift pagi dan shift siang yang menunjukan perbedaan tingkat stres. Untuk tingkat performansi terdapat perbedaan yang signifikan untuk treatment tidur cukup dan tidak tidur baik sebelum simulasi dan setelah simulasi. Sementara untuk treatment tidak tidur dan tidur cukup antar shift menunjukan perbedaan tingkat performansi yang signifikan. Pengujian terhadap variabel dependen (tingkat stres) antara treatment tidur cukup dan tidak tidur pada sebelum dan setelah simulasi menunjukan perbedaan yang signifikan. Pengujian terhadap variabel dependen (tingkat performansi) antara treatment tidur cukup dan tidak tidur pada sebelum dan setelah simulasi menunjukan perbedaan yang signifikan. Hubungan antara tingkat stres dan tingkat performansi menunjukan nilai koefisien korelasi sebesar - 0,4 , artinya hubungan terjadi cukup kuat. Nilai kemiringan tingkat stres terhadap tingkat performansi sebesar -0,025 menunjukan bahwa jika tingkat stres mengalami peningkatan maka tingkat performansi akan mengalami penurunan sebesar 0,025 menit.

Implikasi penelitian ini menunjukan bahwa jika pengemudi mobil pribadi mengalami peningkatan tingkat stres maka performansi atau waktu respon pengemudi akan menurun saat berkendara. Hal tersebut merupakan faktor yang memicu terjadinya kecelakaan saat berkendara. Hasil penelitian ini diharapkan menjadi masukan untuk pemerintahan Kota Bandung maupun Polrestabes Kota Bandung dalam membuat regulasi pengemudi mobil pribadi saat berkendara agar tingkat kecelakaan yang terjadi dapat berkurang. 


\section{Referensi}

[1] Dwiyogo, P., Prabowo. Studi Identifikasi Daerah Rawan Kecelakaan (Blackspot danBlacksite) Pada Jalan Tol Jagorawi. Tugas Akhir, Jurusan Teknik Sipil, Universitas Diponegoro, Semarang, 2006.

[2] Galiard, A.W.K. Concentration, Stress and Performance. Performance Under Stress, 2005, pp. 59-75.

[3] Syahlefi, M.R. Faktor Faktor yang Berhubungan dengan Kelelahan Pengemudi Bus di CV. Makmur. Tugas Akhir, Fakultas Kesehatan Masyarakat, Universitas Sumatra Utara, Medan, 2015.

[4] Dorrian, J., Baulk, S,D,M \& Dawson., D. Work hours, workload, sleep and fatigue in Australian Rail Industry employees. Apllied Ergonomic. 42, 2011, pp. 202-209.

[5] Tarwaka., Bakri, S.H.A., Sudiajeng, L. Ergonomi Untuk Keselamatan, Kesehatan Kerja dan Produktivitas, UNIBA PRESS, Surakarta, 2004.

[6] Kusuma, A.P. Usulan Strategi Peningkatan Kinerja Masinis Dan Asisten Masinis Berdasarkan Faktor Pemicu Stres Kerja Dalam Niosh General Job Stress Questionnaire. Tugas Akhir, Jurusan Teknik Industri, Institut Teknologi Nasional, Bandung, 2011.

[7] Mathews, G. (2002). Towards a transactional ergonomics for driver stress and fatigue. Theoritical Issues in Ergonomics Science, 3(2), pp. 195-211.

[8] Arsyad, D.I. Hubungan Antara Stres Berkendara Dengan Disiplin Berlalu Lintas Pada Pengguna Sepeda Motor Dengan Status Mahasiswa Di Kota Bandung. Departemen Psikologi, Universitas Pendidikan Indonesia, Bandung, 2015.

[9] Underwood, G. Traffic and Transport Psychology: Theory and Application. Amsterdam: Elsevier, 2005.

[10] Dorn, L. Driver Behaviour and Training: Volume III. London: Ashagate, 2008.

[11] Zurika, A. Kajian Tingkat Kelelahan Melalui Evaluasi Beban Mental dan Kantuk pada Pekerjaan Masinis Kereta Api Pandan Wangi. Tugas Akhir, Jurusan Teknik Industri, Institut Teknologi Bandung, Bandung, 2011.

[12] Sutalaksana, Iftikar Z. Teknik Tata Cara Kerja. ITB. Bandung, 1979.

[13] Iridiastadi, H., Yassierli. (2014). Ergonomi suatu pengantar. PT Remaja Rosdakarya. Bandung, 2014.

[14] Milosevic, S. Driver's fatigue studies. Ergonomics, Vol. 40 (3), 1997, pp. 381-389.

[15] http://www.mtstcil.org/skills/stress-deal.html, diakses Maret 2019.

[16] National Transport Commision. Guideline for managing heavy vehicle driver fatigue. National Transport Commision. Melbourne: Australia, 2006.

[17] Talbott, S. The cortisol connection: why stress makes you fat and ruins your health-and what you can do it about it $2^{\text {nd }}$ ed. Hunter House Inc. Alameda, 2007.

[18] http//www.osh.dol.gov.nz/order/catalogue/pdf/stress, diakses Maret 2019.

[19] Vander, A, Sherman, J., dan Luciano, D. S. Human Physiology: The mechanism of body function ( $8^{\text {th }}$ ed). McGrawHill. Boston, MA, 2001.

[20] Yamaguchi, M., Kanemori, T., Kanemaru M., Takai, N., Mizuno Y., Yoshida H. Performance evaluation of salivary amylase activity monitor. Biosensors and Bioelectronic, Vol. 20, pp. 491-497, 2004.

[21] Scalon, V.C., Sanders, T. Essential of anatomy and physiology $\left(5^{\text {th }} e d\right)$. F.A Davis Company. Philadelphia, 2007.

[22] Yamaguchi, M., Kanemori, T., Kanemaru M., Takai, N., Mizuno Y., Yoshida H. Test-strip-type salivary amylase activity monitor and its evaluation. Sensor and Materials, Vol. 15 no.5, pp. 283-294, 2003.

[23] Xu, J., Anders, S., Pruttianan, A., France, D., Lau, N., Adam, J.A., Weinger, M.B. Human performance measures for the evaluation of process control human-system interface in highfidelity simulations. Applied ergonomic, 73, pp.151-165, 2018.

[24] Vazan, R., Filcikova, D., Mravec, B. Effect of the stroop testperformed in supine position on the heart rate variability in both genders. Autonomic Neuroscience: Basic and clinical, 208, pp.156-160, 2017.

[25] Ergen, M., Saban, S., Kimirzi-Alsan, E., Keskin-Ergen, Y., Demiralp, T. Time-frequency analysis of the event-related potentials associated with the stroop test. Internationl Journal of Psychophysiology. INTPSY-10843, 2014.

[26] Walpole, R.E., Myers, R.H., Myers. S.L., Ye, K., Probability \& Statistics for Engineers \& Scientists. Prentice hall, USA, 2012.

[27] Abdurrahman, M. Dasar - Dasar Metode Statistika Untuk Penelitian, Pustaka Setia, Bandung, 2011.

[28] Dajan, Anto. Pengantar Metode Statistik Jilid II, PT Pustaka LP3ES, Indonesia, 1996.

[29] Gujarati, Damodar N., Porter D. C. Dasar-Dasar ekonometrika buku 1. Jakarta : Salemba Empat, 2009.

[30] Nater, M. Nicholas R., Wolf S., Ulrike E., Clemens, K. Determinants of the diurnal course of salivary alpha-amylase. Psycohoneuroendocrinology 32, pp.392-401, 2007.

[31] Wahyuning, C.S., Rahmatiah, I., Sutalaksana, I.Z. Pengaruh lingkungan kerja kabin lokomotif terhadap tingkat stres dan beban kerja mental masinis secara fisiologis. Jurnal Sistem Teknik Industri, Vol.19, no.1 pp.20-29, 2017

[32] Siswanto, D., Loice, R., Chandra, K. Perancangan Alat Deteksi Kantuk Dan Analisis Tingkat Kantuk Pengemudi Bus Malam $X$. LLPM. Universitas Khatolik Parahyangan, Bandung, 2014.

[33] DeCaro, J. Methodological consideration in the use of salivary amylase as a stress marker in field research. American Journal of Human Biology, 20, pp.617-619, 2008.

[34] Noordzij, M., Kitty J.J., Giovanni T, Friedo W. Dekker., Carmine Z, Michael W. T. Sample Size Calculations: Basic Principles And Common Pitfalls. Nephrol Dial Transplant 25, pp.1388-1393, 2010.

[35] Sugiyono. Metode Penelitian Kuantitatif, Kualitatif, dan $R \& D$, Alfabeta, Bandung, 2018. 